\title{
Spectrum of Induction Machine Stator Currents, Affected By Clutch Wobbling and Mixed Eccentricity
}

\author{
Saleh S. Hamad Elawgali \\ Department of Electrical and Electronics Engineering \\ AL-Tahadi University \\ P.O. Box 633 Sirte-Libya \\ tel. +2185460157 / fax. +2185465461 \\ E-mail: elawgali2002@yahoo.com
}

\begin{abstract}
Current spectrum of a four pole-pairs, $550 \mathrm{~kW}$, induction machine were calculated for the cases of full symmetry, clutch wobbling, static and mixed (static + dynamic) eccentricity. The calculations involve integration of 93 electrical plus four mechanical ordinary differential equations. Electrical equations account for variable inductances affected by slotting and eccentricities. The calculations were followed by Fourier analysis of the stator currents in steady state operation.

Zooms of the current spectrums, around the $50 \mathrm{~Hz}$ fundamental harmonic as well as of the main slot harmonic zone, of both calculated and measured currents are included.
\end{abstract}

\section{Key words}

Induction machine, diagnostics, current spectrum, harmonics.

\section{Introduction}

Induction machines are responsible for conversion about $65 \%$ of electrical energy produced all over the world into mechanical energy. Hence, diagnosing such machines is a very important issue.

Mature procedures have been elaborated by many researches [1] [2] [3] dealing with diagnosing cage asymmetries. Development of these procedures can be supported by induction machine models recognizing only the fundamental harmonic. By contrast to this, the models admitting static or/and dynamic eccentricities have to be based on poly-harmonic models.

The calculations presented in this paper are based on the poly-harmonic model accounting for static and dynamic eccentricity, stator and rotor slotting, parallel branches as well as cage asymmetry.

The calculations presented in [4] [5] are based on the poly-harmonic model accounting for static and dynamic eccentricity, stator and rotor slotting, parallel branches as well as cage asymmetry. In addition, in [6] the effect of the polluted supply voltage on the current spectrum was accounted for as well.
This paper, will present the effect of the clutch wobbling as well as the mixed eccentricity on the spectrum of the induction machine stator currents. The paper will also present the possibility of distinguishing between each ailment via comparing the un-normal harmonics contained in stator current spectrums in each case.

The spectrums presented in this paper rely on calculations performed with special software owned by the Chair of Electrical Machines, AGH University of Science and Technology.

The program for dynamics simulation consists of four base classes [7]:

- Class Pa1 calculates mainly leakage inductances.

- Class In16 calculates self and mutual main inductances accounting for true stator winding configuration as well as for slotting and eccentricity.

- Class De18 calculates derivatives of the inductances, with respect to rotor angle.

- Class Dy20 performs integration of differential equations using 3D matrices of inductances and their derivatives stored on the disk by class De18.

The spectral analysis was performed by program Sp1 that calculates Fast Fourier Transform (FFT) as well as least squares approximation of the fundamental component of the stator currents.

The calculations performed refer to the $550 \mathrm{~kW}$ squirrelcage induction machine, with 4-pole pairs $(\mathrm{p}=4)$ and $\mathrm{N}_{\mathrm{S}} / \mathrm{N}_{\mathrm{R}}=72 / 88$ of stator/rotor slots. All spectrums refer to steady state operation by full loading torque TL $=7050$ $\mathrm{Nm}$.

\section{Full symmetry}

In order to provide reference basis the calculations have been performed for the case of fully symmetrical machine (no eccentricity, no wobbling). The full spectrum of the stator line current is shown in figure 1. It contains the $50 \mathrm{~Hz}$ fundamental harmonic as well as the main slot harmonic, of the frequency of about $1140.7 \mathrm{~Hz}$, and amplitude of about -33dB. The frequency of the main slot harmonic can be predicted by the following formula: 


$$
\mid f_{1}+h \cdot N R(1-s) n_{s}
$$

Where: the supply frequency $f_{1}=50 \mathrm{~Hz}$, the parameter $h$ $=1$ [8], $N_{R}=88$, the slip s $=0.00846$, and the synchronous speed $n_{s}=f_{I} / p=12.5$ revolutions per second. In addition, the spectrum contains the second slot harmonic, of the frequency of about $2130 \mathrm{~Hz}$, which is out of our interest.

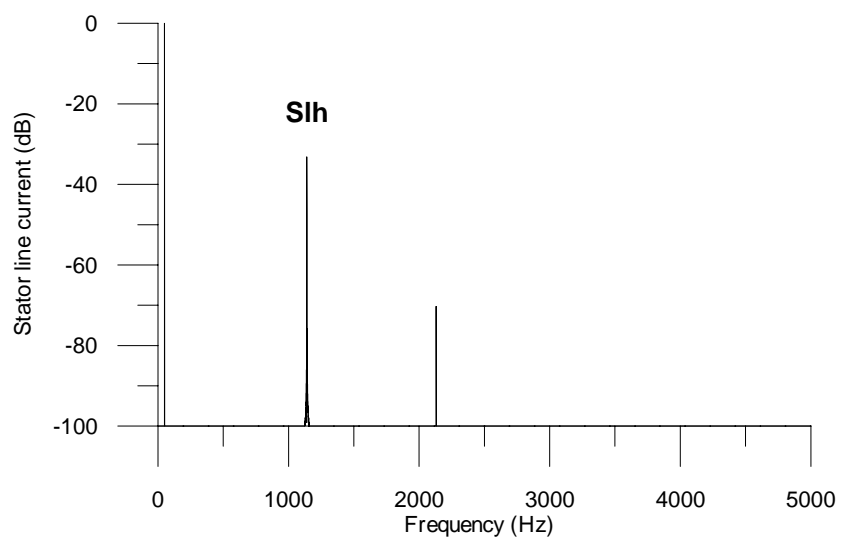

Figure1. Spectrum of the stator current (full symmetry)

\section{Clutch wobbling}

When the shaft of the electrical machine is not fully lined with the shaft of the loading machine this will result in some alternating torque components, superimposed on the torque transmitted through the clutch. This phenomenon is referred to as the clutch wobbling.

The spectrum of figure 2a refers to the case of $2 \%$ wobbling of the clutch torque. In this spectrum the rotational harmonics are quite conspicuous around the 50 $\mathrm{Hz}$ fundamental harmonic as well as around the main slot harmonic. The zoom of figure 2a around the $50 \mathrm{~Hz}$ harmonic is shown in figure $2 \mathrm{~b}$. It contains just one pair of rotational harmonics, $\mathbf{r}_{+1}$ and $\mathbf{r}_{-1}$, in the fundamental harmonic zone. These rotational harmonics are spaced by $\pm(1-s) f_{l} / p$ around the $50 \mathrm{~Hz}$ harmonic. Their amplitudes are of about $-47 \mathrm{~dB}$. Similarly, figure2c shows the zoom of the main slot harmonic zone. It contains also one pair of slot-zone rotational harmonics, $\mathbf{r s}_{\mathbf{+}}$ and $\mathbf{r s}_{\mathbf{- 1}}$. They are spaced by $\pm(1-s) f_{1} / p$ to the right and left of the main slot harmonic Slh, and their amplitudes are of about $-65 \mathrm{~dB}$.

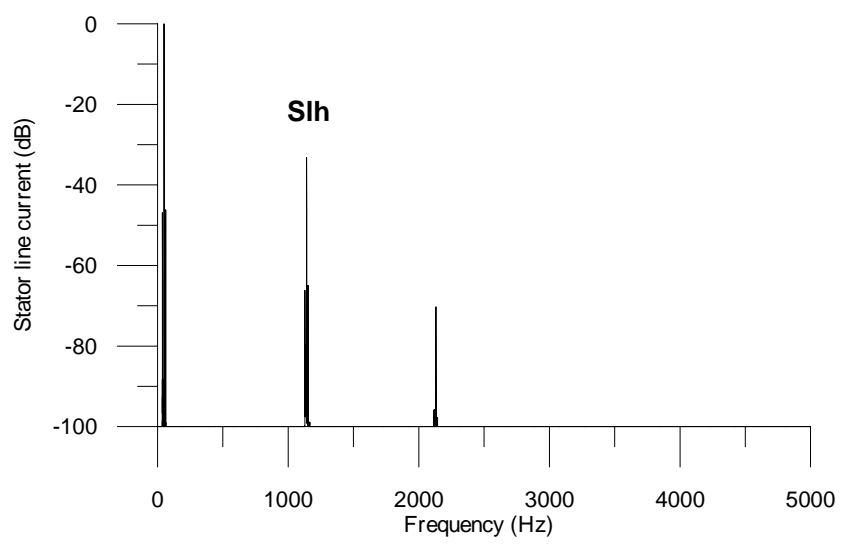

Figure2a. Spectrum of the stator current (2\% clutch wobbling)

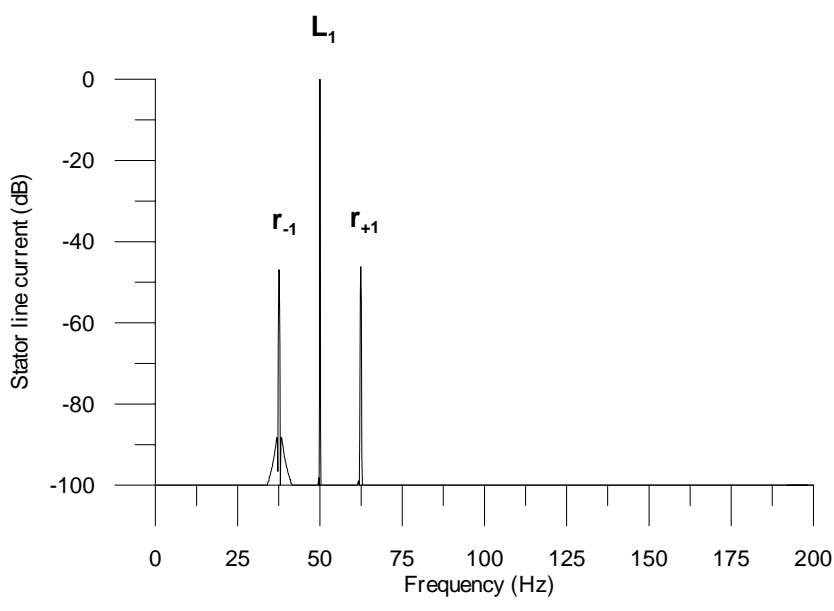

Figure2b. Zoom around $50 \mathrm{~Hz}$ (2\% clutch wobbling)

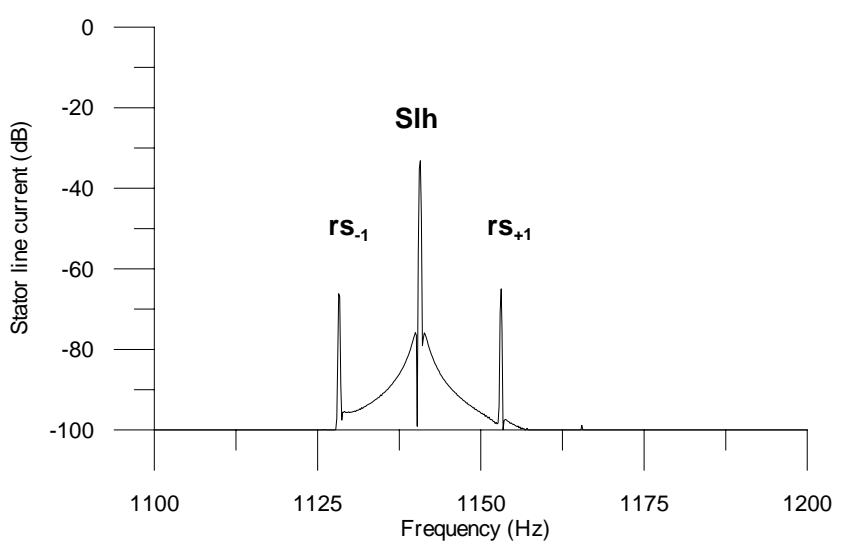

Figure2c. Zoom of the main slot harmonic zone ( $2 \%$ clutch wobbling)

\section{Mixed eccentricity}

The stator current spectrum shown in fig. 3a refers to the case of mixed eccentricity ( $60 \%$ static $+20 \%$ dynamic). The spectrum contains many of rotational harmonics in the $50 \mathrm{~Hz}$ fundamental harmonic zone as well as in the main slot harmonic zone. Also, the rotational harmonics present in the second slot harmonic zone but they are out of our interest. The zoom of the fundamental harmonic zone is shown in fig. 3b. The sequence of rotational harmonics is clearly visible around the fundamental harmonic. They are spaced by $\pm(1-s) n f_{l} / p$ above and below the $50 \mathrm{~Hz}$ harmonic, where $n$ is the order of these rotational harmonics amounting to $n= \pm 1, \pm 2, \pm 3, \ldots$. The first order rotational harmonics $\mathbf{r}_{-1}$ and $\mathbf{r}_{+1}$, of the frequencies of about 37.5 and $62.5 \mathrm{~Hz}$, respectively, are the most conspicuous ones, having the amplitudes of about $-51 \mathrm{~dB}$. Similarly, in figure 3c of the main slot harmonic zone, the mixed eccentricity rotational harmonics are present around the main slot harmonic Slh as well as around the twin harmonic tw of the frequency of about $1040 \mathrm{~Hz}$. All the mixed eccentricity rotational harmonics are spaced by about $\pm(1-s) n f_{1} / p$ above and below either the main slot harmonic or the twin harmonic. The first order mixed eccentricity rotational harmonics, $\mathbf{m s}_{+\mathbf{1}}$ and $\mathbf{m s}_{-\mathbf{1}}$, around the main slot harmonic are the most conspicuous ones having amplitudes of about $-53 \mathrm{~dB}$. 
The presence of the twin harmonic tw, of the frequency of about $1040 \mathrm{~Hz}$, gives clear evidence for the existence of the static eccentricity, $60 \%$ in this case.

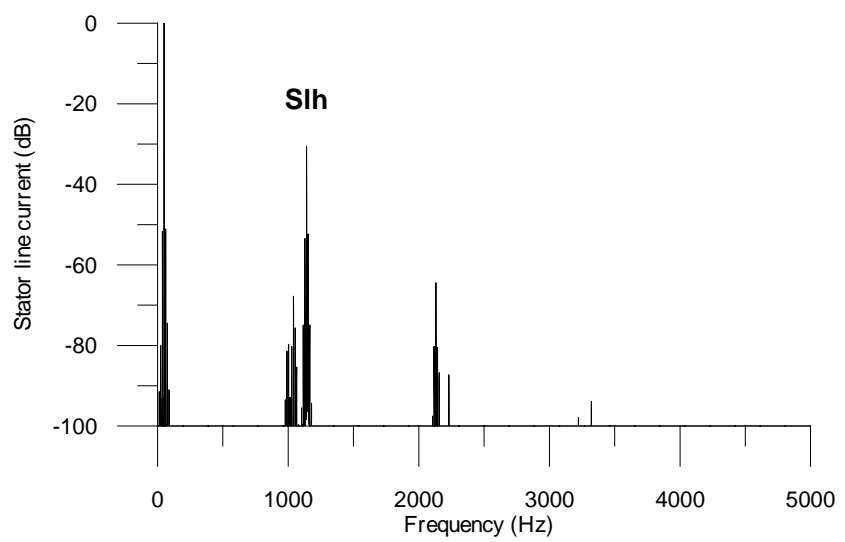

Figure3a. Spectrum of the stator current

(60\% static $+20 \%$ dynamic eccentricity)

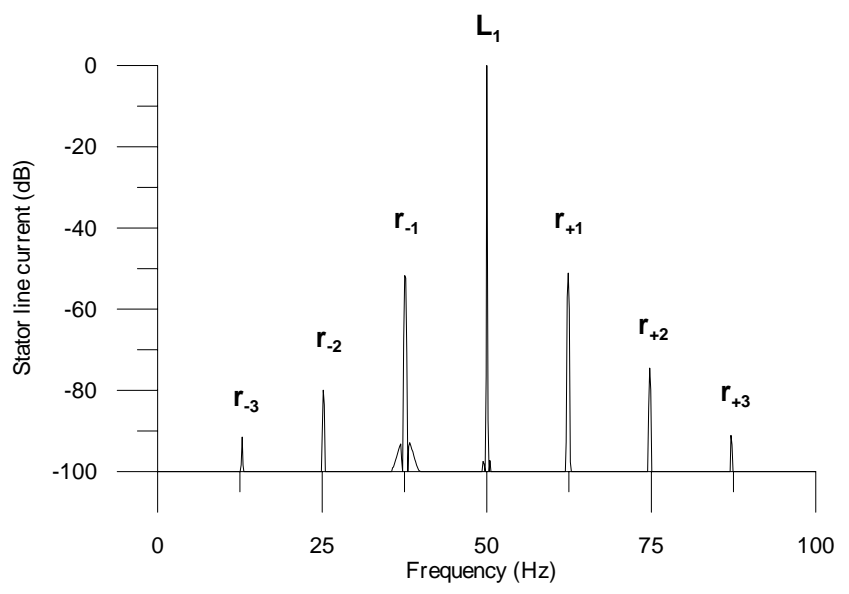

Figure3b. Zoom around $50 \mathrm{~Hz}$ (60\% static $+20 \%$ dynamic eccentricity)

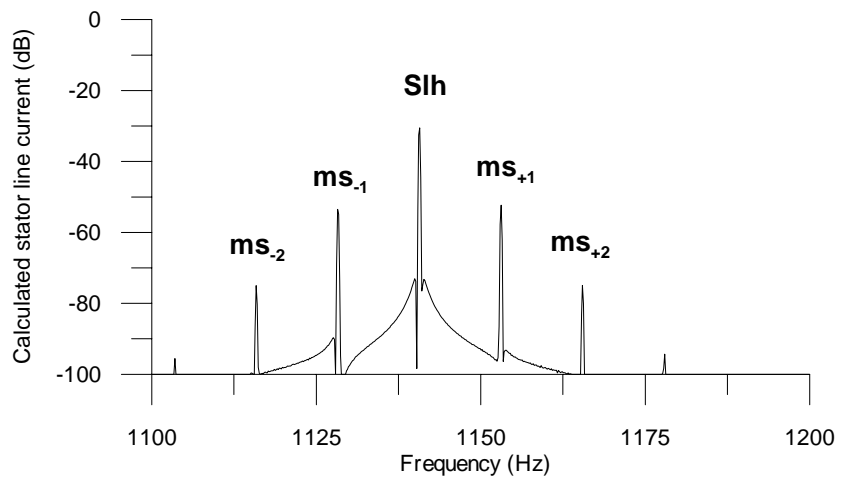

Figure3c. Zoom of the main slot harmonic zone (60\% static $+20 \%$ dynamic eccentricity)

\section{Case studies}

Spectral analyses have been performed for a number of currents really registered in the industry. The currents analyzed refer to a number of four pole pairs, $550 \mathrm{~kW}$ induction machines, labeled in the industry as WS.

The registered currents have been taken from the data base owned by the Chair of Electrical Machines, AGH University of Science and Technology.

The analyses were focused on diagnosing static, dynamic and mixed eccentricities as well as clutch wobbling.

Among all the cases analyzed the two following cases were found to show up high degree of clutch wobbling and mixed eccentricity, respectively. (File names 2WS1obc2 of 07.11.2003 and 4WS2U1 of 16.11.2004).

\section{Clutch wobbling plus static eccentricity}

The full spectrum of the measured stator current is shown in figure 4a. The zoom around the fundamental harmonic is shown in figure $4 \mathrm{~b}$. The first order rotational harmonics $\mathbf{r}_{+\mathbf{1}}$ and $\mathbf{r}_{-1}$ are clearly visible around the $50 \mathrm{~Hz}$ harmonic. Similarly, the zoom of the main slot harmonic zone shown in figure $4 c$ contains one pair of slot zone rotational harmonics, $\mathbf{r s}_{\mathbf{+}}$ and $\mathbf{r s}_{\mathbf{- 1}}$, around the main slot harmonic Slh that gives clear evidence for the clutch wobbling. Also, the twin harmonic tw, of the frequency of about $1040 \mathrm{~Hz}$, is quite conspicuous which proves the existence of the static eccentricity in addition to the clutch wobbling in this case.

For comparison, the current spectrum of the same machine was calculated for the case of $2 \%$ clutch wobbling plus $60 \%$ static eccentricity (figure $5 a$ ). The calculations have been performed accounting for the deformation of the supply voltage caused by the harmonics of the orders of 2, 3, 5 and 7, with frequencies of 100, 150, 250 and $350 \mathrm{~Hz}$, respectively.

Referring to the measurements [9] and to the limits imposed by the standards [10] the following values of the $2^{\text {nd }}, 3^{\text {rd }}, 5^{\text {th }}$ and $7^{\text {th }}$ harmonics have been assumed for calculations: $0.05 \%, 0.25 \%, 1 \%$ and $0.2 \%$ respectively. The zooms, around the $50 \mathrm{~Hz}$ and of the first slot harmonic zone, of figure $5 a$ are shown in figures $5 b$ and $5 c$ respectively. 


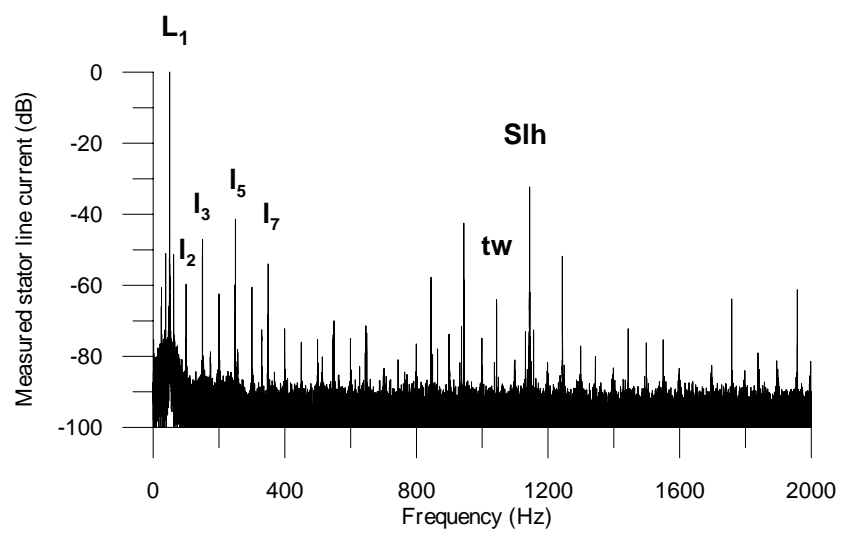

Figure4a. Spectrum of the measured stator current

(2WS1, 4 pole pairs, $550 \mathrm{~kW}$ Induction machine)

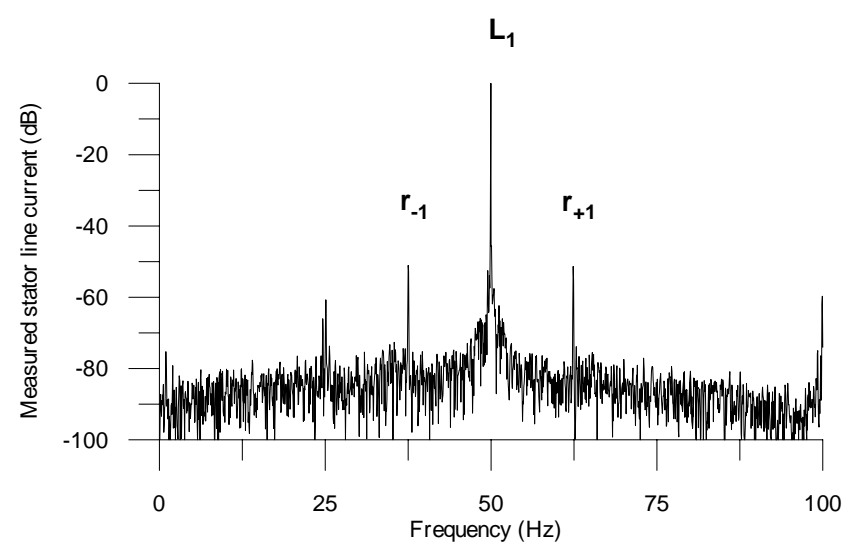

Figure4b. Zoom around $50 \mathrm{~Hz}$ of the measured stator current

(2WS1, 4 pole pairs, $550 \mathrm{~kW}$ Induction machine)

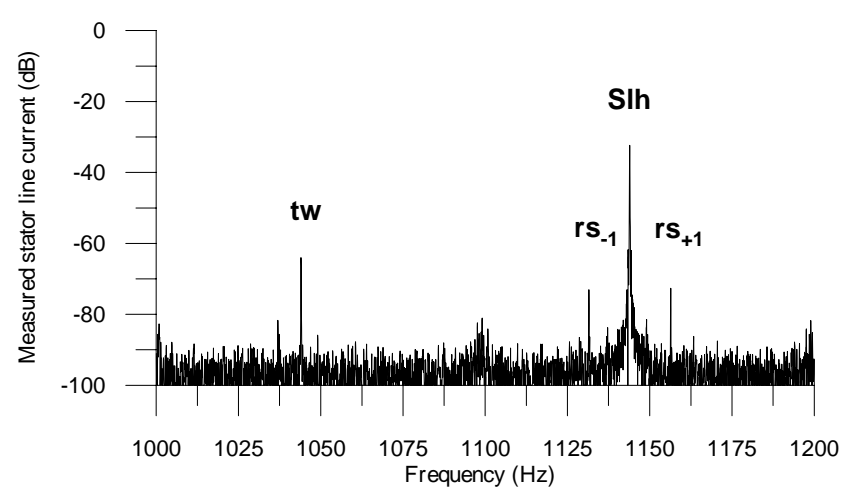

Figure4c. Zoom of the main slot harmonic zone of the measured stator current (2WS1, 4 pole pairs,

$550 \mathrm{~kW}$ Induction machine)

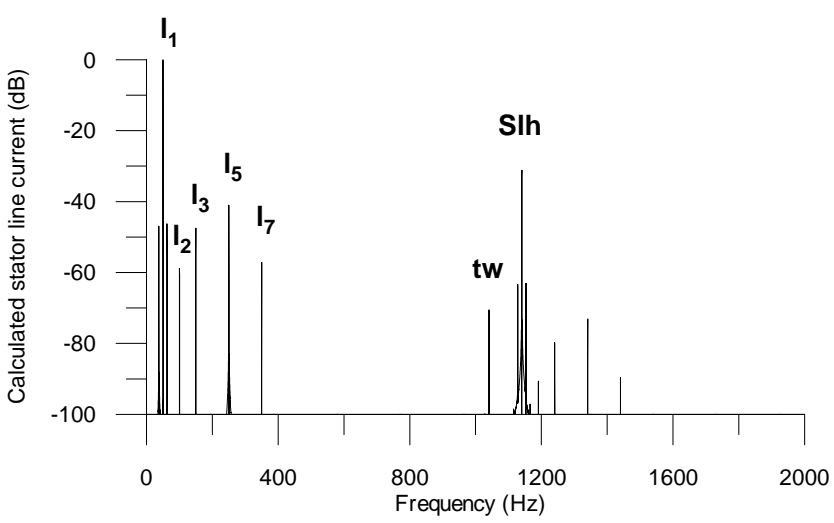

Figure5a. Spectrum of the calculated stator current (2\% clutch wobbling $+60 \%$ static eccentricity, deformed supply voltage)

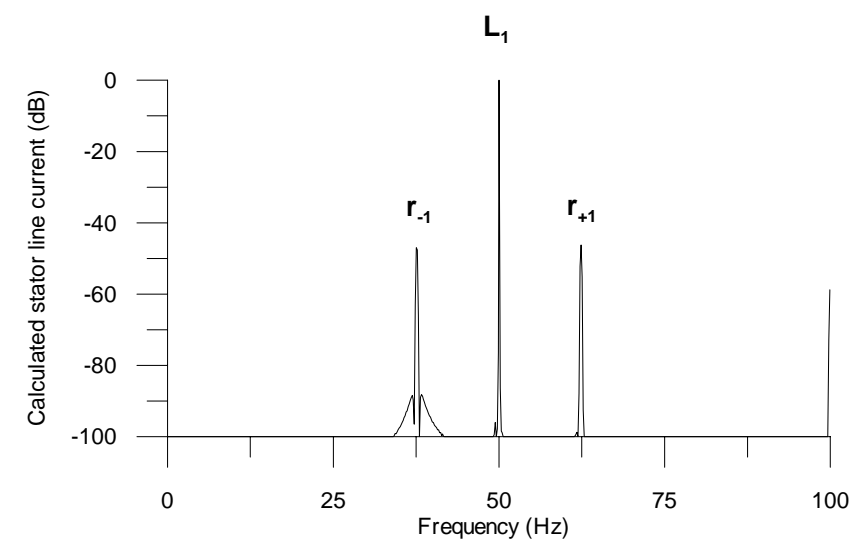

Figure5b. Zoom around $50 \mathrm{~Hz}$ of the calculated stator current ( $2 \%$ clutch wobbling $+60 \%$ static eccentricity, deformed supply voltage)

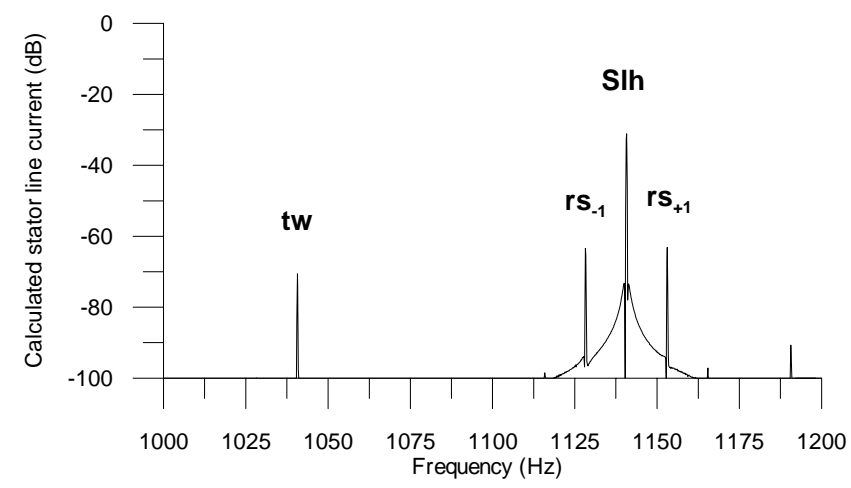

Figure5c. Zoom of the main slot harmonic zone of the calculated stator current ( $2 \%$ clutch wobbling $+60 \%$ static eccentricity, deformed supply voltage)

\section{Mixed eccentricity}

The full spectrum of the measured stator current is shown in figure 6a. The zoom around the fundamental harmonic is shown in figure $6 \mathrm{~b}$. The sequence of rotational harmonics is clearly visible around the $50 \mathrm{~Hz}$ harmonic. Similarly, the zoom of the main slot harmonic zone, shown in figure 6c, contains the first and second order mixed eccentricity rotational harmonics around the main 
slot harmonic that gives clear indication for the existence of the mixed eccentricity.

Also, the rotational harmonics are quite conspicuous around the twin harmonic tw, of the frequency of about $1040 \mathrm{~Hz}$. That additionally supports the conclusion about the existence of the mixed eccentricity in this case.

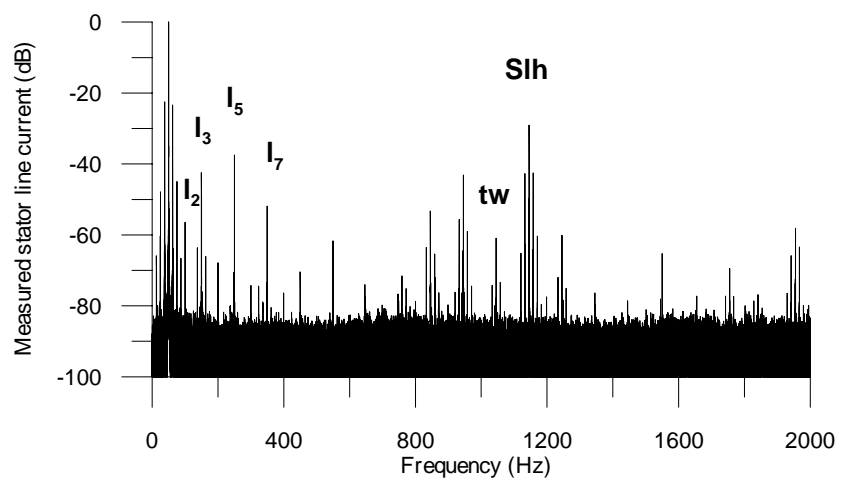

Figure6a. Spectrum of the measured stator current

(4WS2, 4 pole pairs, $550 \mathrm{~kW}$ Induction machine)

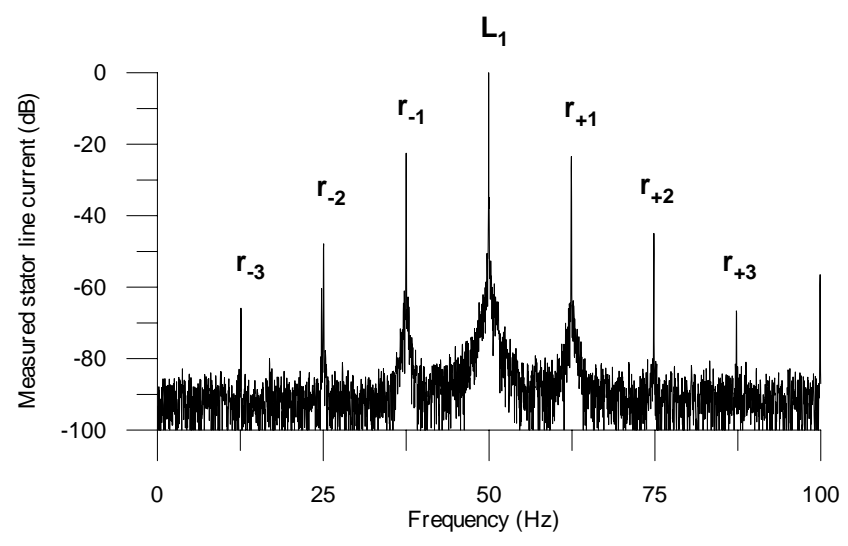

Figure6b. Zoom around $50 \mathrm{~Hz}$ of the measured stator current (4WS2, 4 pole pairs, $550 \mathrm{~kW}$ Induction machine)

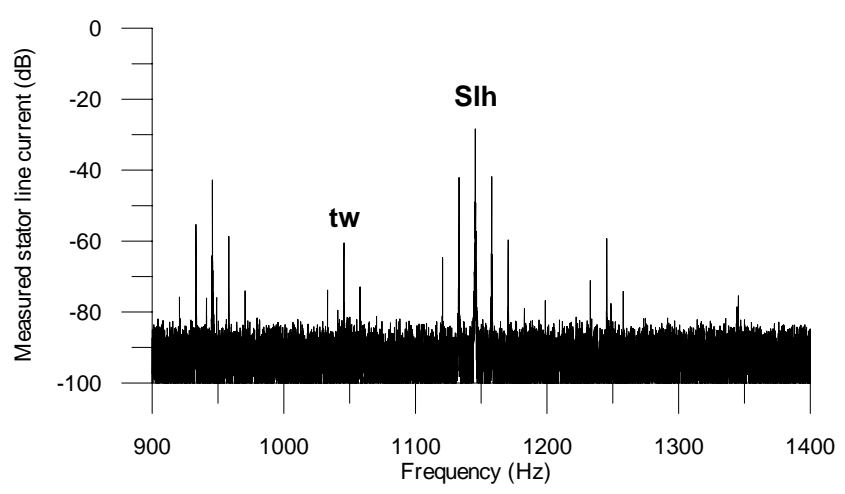

Figure6c. Zoom of the main slot harmonic zone of the measured stator current (4WS2, 4 pole pairs, $550 \mathrm{~kW}$ Induction machine)

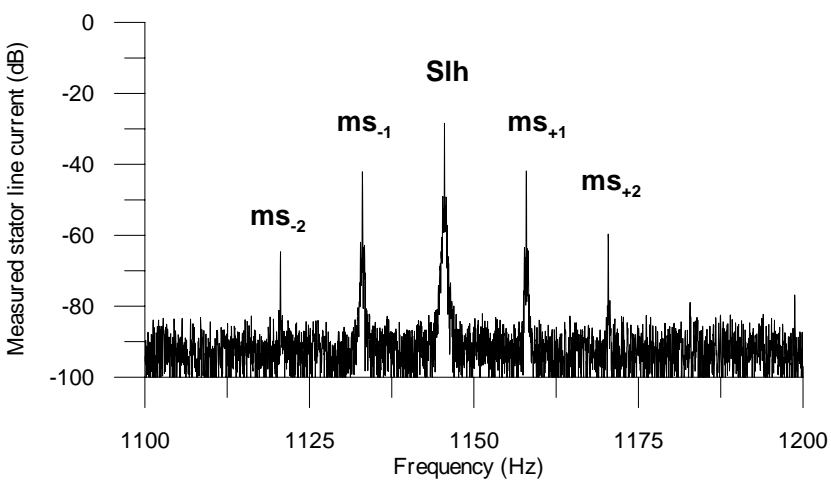

Figure6d. Zoom around the main slot harmonic of the measured stator current (4WS2, 4 pole pairs, $550 \mathrm{~kW}$ Induction machine)

\section{Conclusion}

The Calculations performed and the case studies allow concluding that:

1. The clutch wobbling is always accompanied by a pair of rotational harmonics spaced by $\pm(1-s)$ $f_{l} / p$ around the $50 \mathrm{~Hz}$ fundamental harmonic as well as around the main slot harmonic.

2. The mixed eccentricity is always accompanied by sequence of rotational harmonics spaced by $\pm(1-s) n f_{1} / p$ around the $50 \mathrm{~Hz}$ harmonic as well as around the main slot harmonic.

3. The presence of the twin harmonic in the main slot harmonic zone gives clear evidence for the existence of the static eccentricity.

4. Quantitative calculations deliver solid base for reliable diagnosis of induction machines and differentiating between different ailments.

\section{References}

[1] Bellini, A., Filippetti, F., Franceschini, G. and Tassoni, C. "Towards Correct Quantification of Induction Machines Broken Bars Through Input Electrical Signals", International Conference on Electrical Machines (ICEM'2000), pp. 781-785, 2830 August 2000, Espoo, Finland.

[2] Bellini, A., Filippetti, F., Franceschini, G. and Tassoni, C. (2001), "Quantitative Evaluation of Induction Motor Broken Bars by Means of Electrical Signature Analysis”, IEEE, Transactions on Industry Applications, Vol. 37 No. 5, pp. 1248-55.

[3] A. Lebaroud, A. Bentousi, A. Kkhezzar, M. Boucherma. "Effects of Broken Bar of InductionMotor with Stator Asymmetry and DistortedSupply ", International Conference on Electrical Machines (ICEM'2004), pp. 795-796, 5-8 September 2004, Cracow, Poland.

[4] Saleh Elawgali. "Effect of Combined Eccentricities on the Spectrum of Induction Machine Currents", $X L$ International Symposium on Electrical Machines (SME'2004), pp. 457-462,

15-18 June 2004, Hajnowka, Poland.

[5] Saleh Elawgali. "Current Spectrums of a 3.15 MWInduction Machine Based on Diagnostic Oriented Calculations ", Elektrotechnika i Elektronika, AGH Uczelniane Wydawnictwa Naukowo-Dydaktyczne, pp. 14-26, Krakow 2004, tom 23. zeszyt 1. 
[6] Saleh Elawgali. "Effect of Eccentricities and Cage Asymmetry on the Induction Machine Currents, Considering Deformation of Supply Voltages”, International Conference on Electrical Machines (ICEM'2004), pp.443-444, 5-8 September 2004, Cracow, Poland.

[7] J. Rusek, "Computer Implementation of Induction Machine Dynamical Model Accounting for Broken Bars, Eccentricities, Slotting and Parallel Branches”, International Conference on Electrical Machines (ICEM'2000), pp. 868-872, 28-30 August 2000, Espoo, Finland.

[8] J. Rusek, "Categorization of Induction Machines Resulting from Their Harmonic-Balance Model”, Electromagnetics, 23, pp. 277-292, 2003, Taylor \& Francis.
[9] W. Rams, J. Rusek, "Induction-Machine Cage State Diagnosis By Supply From Two Phases” $X X X$ Sympozjum Maszyn Elektrycznych Współczesne Problemy Maszyn Indukcyjnych, pp. 389-394, 13-17 June 1994, Kazimierz Dolny, Poland.

[10] Regina Lamedica, Alberto Prudenzi, Enrico Tironi And Dario Zaninelli, "Analysis of Harmonic Distortion Limits In IEC and IEEE Standards”, $5^{\text {th }}$ International Conference, Electrical Power Quality And Utilization, pp. 93-99, 15-17 September 1999, Krakow, Poland. 